\title{
Effects of hydroxyethyl starch 130/0.4 on the kidney tissue of rats with ureteral obstruction
}

This article was published in the following Dove Press journal:

Drug Design, Development and Therapy

\author{
Ișın Güneș' \\ Nuran Süngü ${ }^{2}$ \\ Aydan Kılıçarslan ${ }^{2}$ \\ Volkan Șıvgın³ \\ Metin Alkan ${ }^{3}$ \\ Ayșegül Küçük ${ }^{4}$ \\ Hakan Boyunağa ${ }^{5}$ \\ Yusuf Ünal ${ }^{3}$ \\ Mustafa Arslan ${ }^{3}$ \\ 'Department of Anaesthesiology \\ and Reanimation, Erciyes University \\ Medical Faculty, Kayseri, Turkey; \\ ${ }^{2}$ Department of Pathology, Yıldırım \\ Beyazıt University Medical Faculty, \\ Ankara, Turkey; ${ }^{3}$ Department of \\ Anaesthesiology and Reanimation, \\ Gazi University Medical Faculty, \\ Ankara, Turkey; ${ }^{4}$ Department of \\ Physiology, Dumlupınar University \\ Medical Faculty, Kütahya, Turkey; \\ ${ }^{5}$ Department of Biochemistry, \\ Kırıkkale University Medical Faculty, \\ Kırıkkale, Turkey
}

Objective: This study was conducted since the effects of colloid solutions on the renal system remain controversial and need to be adequately studied in animals. We aimed to evaluate the effects of hydroxyethyl starch (Voluven) on the kidney tissue of rats with late renal failure due to ureteral obstruction.

Materials and methods: Rats were divided into four groups: Group C, control; Group HES, hydroxyethyl starch solution (HES) 130/0.4 (Voluven ${ }^{\circledR}$ ); Group UUO, unilateral ureteral obstruction (UUO); and Group UUO-HES, UUO-HES 130/0.4 (Voluven ${ }^{\circledR}$ ). In the groups with ureteral obstruction, the distal part of the right ureter was accessed and sutured through a lower abdominal incision under ketamine anesthesia. Any signs of late-stage renal failure were evaluated after three weeks. Rats in the HES group and the renal failure-HES group were administered with HES 130/0.4 as a single intravenous dose of $20 \mathrm{~mL} / \mathrm{kg}$. After a follow-up of 24 hours, intra-abdominal blood sample was collected, and the rats were sacrificed. Biochemical and histopathological parameters were then evaluated.

Results: Ureteral obstruction significantly increased urea and creatinine levels. In addition, when the UUO-HES and HES groups were compared, the administration of HES increased urea and creatinine levels in the UUO-HES group. Nitric oxide enzyme activity and malondialdehyde levels have significantly increased in the UUO groups. In addition, HES significantly increased nitric oxide activity and malondialdehyde levels in the UUO-HES group, in comparison with the HES group. The activity of caspases 3 and 8 was significantly increased in the UUO groups. In addition, HES significantly increased the activity of caspases 3 and 8 in the UUO-HES group, in comparison with the HES group. Light microscopy revealed significant changes in the UUO groups, especially in the obstructed kidneys.

Conclusion: If indicated, HES should be used with caution in cases of UUO, but not in the cases of bilateral ureteral obstruction. Other aspects of these findings, including the clinical significance and practical applications, merit further experimental and clinical investigation.

Keywords: unilateral ureteral obstruction, hydroxyethyl starch solution 130/0.4, caspase 3, caspase 8 , malondialdehyde, nitric oxide

\section{Introduction}

Hydroxyethyl starches are the most frequently used compounds for their considerable and long-lasting blood volume-expanding effects. ${ }^{1}$ A review of the available clinical data demonstrates that hyperoncotic colloids and starches with a molar substitution $>0.4$ may have harmful effects on the kidneys of patients with septic shock. ${ }^{2-4}$ As a third-generation hydroxyethyl starch (HES), tetrastarch (molar degree of substitution 0.4 and medium molecular weight of $130 \mathrm{kDa}$ ) reportedly has a more favorable safety profile; however, new concerns have been raised in the use of HES for volume therapy. ${ }^{5,6}$
Correspondence: Mustafa Arslan Department of Anaesthesiology and Reanimation, Gazi University Medical Faculty, 06510 Ankara, Turkey Tel/fax+90 3/2 2026739

Email mustarslan@gmail.com 
In comparison with crystalloids, the effects of HES on renal function in the cardiac surgical setting have been debated in the literature. One study described the beneficial effects of HES, even though the HES-treated patients were subjected to a relatively high exposure of 3,500 $\mathrm{mL}$ in 24 hours. ${ }^{7}$ A large, prospective, randomized study on modern HES, albumin, and crystalloid solutions included $80 \mathrm{HES}$-treated patients subjected to a relatively high exposure (mean of 2,500 mL HES intraoperatively). An increase in creatinine levels was observed only in the HES and albumin groups. Among various studies, the volume regimens, HES dosages, investigated parameters, and observation periods differed..$^{8,9}$

When comparing the effects of HES with those of albumin on renal function in the cardiac surgical setting, the beneficial effects of HES have been described with highdose substitution $(42 \mathrm{~mL} / \mathrm{kg})$, as well as moderate dosages $(<20 \mathrm{~mL} / \mathrm{kg}$ ). However, adverse effects on renal function have been reported, when just $500 \mathrm{~mL}$ HES (corresponding to $6.6 \mathrm{~mL} / \mathrm{kg}$ for $75 \mathrm{~kg}$ body weight) was administered exclusively during priming. One possible mechanism of damage is the increased colloid osmotic pressure, described in an experimental animal model..$^{8,10-12}$

The unilateral ureteral obstruction (UUO) experimental model is especially specific for obstructive nephropathy that results in renal tubular apoptosis and interstitial fibrosis. ${ }^{13,14}$ Apoptosis of renal tubular epithelial cells is one of the important detrimental events which leads to chronic kidney injury and results in renal fibrosis. ${ }^{10,15}$ After UUO, persistent hypoxia increases cytokine levels and stimulates the overproduction of reactive oxygen species (ROS), such as malondialdehyde (MDA). As a key component in this process, MDA mediates autophagy and apoptosis. Caspases (cysteinyl aspartatespecific proteases) play an important role in apoptosis, which entails a complex mechanism and process. ${ }^{16,17}$ The role of angiotensin II (ATII) in the pathophysiology of unilateral obstructive nephropathy has been established; however, there is a lack of studies on comparisons between the effects of angiotensin-converting enzyme (ACE) inhibition and AT1 antagonism on apoptosis in the renal tubule and interstitial cells. An association between the inhibition of ACE and increased nitric oxide (NO) generation has been well established. ${ }^{18}$

In this study, our aim was to investigate the effects of HES on the renal tissue of rats with late-stage renal failure, after ureteral obstruction.

\section{Materials and methods}

\section{Animals and experimental protocol}

The study was approved by the Experimental Animals Ethics Committee of Gazi University and conducted at the GUDAM
Laboratory of Gazi University (14/03/2017-E.38663 GÜET17.014). The experimental procedures were performed in accordance with the standards of the Guide for the Care and Use of Laboratory Animals.

This study was performed in a pathogen-free environment. The animals had free access to food and water. Food and water were withdrawn 2 hours before the start of the procedures. Rats were maintained on a 12:12 light/dark cycle for at least 1 week before the start of the experiment.

Twenty-four male Wistar albino rats weighing between 225 and $275 \mathrm{~g}$ were randomly separated into four groups. The control (C) group (control; n=6); HES 130/0.4 group (HES 130/0.4; n=6); UUO for 3 weeks group (UUO; n=6); and UUO-HES group (UUO $20 \mathrm{~mL} / \mathrm{kg}$, HES 130/0.4; n=6). The control and UUO groups were only given normal saline at the same volume as that administered for the treatment.

All four groups were subjected to $100 \mathrm{mg} / \mathrm{kg}$ ketamine anesthesia intraperitoneally and the right ureter was sutured with 2.0 Mersilene through a low abdominal incision. The suture was left intact for 3 weeks to induce late-stage renal failure.

At the end of the 3-week period, anesthesia was induced using $100 \mathrm{mg} / \mathrm{kg}$ ketamine intraperitoneally, and $20 \mathrm{~mL} / \mathrm{kg}$ HES 130/0.4 was then administered over 15 minutes intravenously through the tail vein. After the follow-up period of 24 hours, $100 \mathrm{mg} / \mathrm{kg}$ ketamine was again administered intraperitoneally, and blood samples were taken from the abdominal aorta of each rat. The serum was stored at $-20^{\circ} \mathrm{C}$ for subsequent analysis of urea, creatinine, MDA, and NO levels. The tissues of both kidneys were sampled and fixed in $10 \%$ buffered formalin for histological analysis.

\section{Immunohistochemical evaluation}

For immunohistochemical evaluation, the surface sections were prepared from formalin-fixed paraffin-embedded blocks of the biopsy specimens. All slides on which the sections were placed were first coated with 3-4 $\mu \mathrm{L}$ poly-L-lysine. The sections were left overnight at $45^{\circ} \mathrm{C}$.

The methods conducted for standard antigen retrieval were as follows: deparaffinization, blocking, application of the primer antibody (caspase 3 and caspase 8: citrate 30 minutes), post-primer, polymer, and diammonium phosphate in a Bond-maximal immunohistochemistry device (Leica Microsystems, Wetzlar, Germany), to evaluate the activity of caspase 3 (p11, C-6, 1/400, mouse monoclonal antibody) and caspase 8 (Clone, D-8, 1/205, mouse monoclonal antibody) antibodies immunohistochemically. Hematoxylin II was applied for 6 minutes, and Blue reagent was then applied for 4 minutes as the background 
dye. Immunohistochemical staining preparations were then washed with water and alcohol. After being clarified with xylene, they were then covered with balsam.

During immunohistochemical staining, both the abundance and intensity of stromal cells and endothelium cytoplasmic staining of caspase 3 and caspase 8 were evaluated. Staining intensity was scored as 0 : no staining; 1 : mild; and 2: severe. If the staining was $>50 \%$, it was evaluated as widespread.

For caspase 8 and caspase 3, thymus tissue and liver tissue were used as controls. Cytoplasmic membranous staining of caspases 3 and 8 was considered positive.

\section{Measurements of MDA levels and NO activity}

Lipid peroxidation was measured using the Esterbauer method. Briefly, MDA reacted with thiobarbituric acid at $90^{\circ} \mathrm{C}-95^{\circ} \mathrm{C}$ and thereby yielded pink chromogranin. Specimens were rapidly cooled and absorbances were then read at $532 \mathrm{~nm}$ spectrophotometrically. Results were presented as $\mathrm{nmol} / \mathrm{g}$ tissue protein. ${ }^{19}$ Stable oxidative NO metabolites $\left(\mathrm{NO}_{2}-\mathrm{vs} \mathrm{NO}_{3}-\right)$ were measured in the serum, and to determine, NO production was measured. The Griess reaction was used in order to measure the nitrite concentration. ${ }^{20}$

\section{Urea and creatinine measurement}

Urease and glutamate were measured by kinetic testing with dehydrogenase, using urea (Ureal, Cobas ${ }^{\circledR}$ ) and the Roche Diagnostics Cobas C501 autoanalyzer. Creatine (Crej2, Cobas $^{\circledR}$ ) was measured by the kinetic colorimetric test (based on the Jaffe method) on the C501 autoanalyzer (Hoffman-La Roche Ltd., Basel, Switzerland). ${ }^{21}$

\section{Statistical analysis}

All data were processed by variance analysis using the Statistical Package for the Social Sciences 20.0 program (IBM Corporation, Armonk, NY, USA) for Windows statistical software. Kruskal-Wallis test was used to assess the results. The Bonferroni adjusted Mann-Whitney $U$ test was used after significant Kruskal-Wallis test results to determine the group differences. The data were expressed as mean \pm standard error (SE). A $p$-value $<0.05$ was considered statistically significant.

\section{Results}

Significant differences were found among the groups, in terms of peritubular capillary caspase 8 activity of the kidneys with ureteral obstruction. Peritubular capillary caspase 8 activity was notably higher in all experimental groups than in the control group ( $p=0.001, p<0.0001, p<0.0001)$. Glomerular and tubular caspase 8 activity was identical among all groups $(p=0.083)$ (Table 1$)$.

Differences among the groups were significant, in terms of caspase 8 enzyme activity of renal peritubular capillaries without ureteral obstruction. Peritubular capillary caspase 8 activity was notably higher in the UUO and UUOHES groups, in comparison with the control group ( $p=0.002$, $p=0.002$ ). Glomerular and tubular caspase 8 enzyme activity was similar among all groups (Table 2).

Differences among the groups with ureteral obstruction were notable in terms of cortical tubular, medullary tubular, and glomerular endoplasmic caspase 3 activity. Caspase 3 enzyme activity of the cortical tubule, medullary tubule, and glomerular cytoplasm was notably higher in the UUO and UUO-HES groups, in comparison with the control and HES groups. In addition, corticomedullary tubulo-cytoplasmic caspase 3 enzyme activity was significantly higher in the UUO-HES group, in comparison with the control and HES groups ( $p=0.005, p=0.005$, respectively) (Table 3; Figures 1-4).

A significant difference was noted among the groups without ureteral obstruction in terms of medullary tubule cytoplasmic activity of caspase 3 . This activity was notably higher in all groups, as compared to the control ( $p=0.002$, $p<0.0001, p<0.0001$, respectively). The activity of caspase 3 was similar in the cortical tubules, corticomedullary tubules, and glomerular cytoplasm $(p=0.269, p=0.077$, and $p=0.235$, respectively) (Table 4).

Significant differences were noted among the groups with ureteral obstruction, in the cortical tubule, corticomedullary tubule, and medullary tubule luminal caspase 3 activity

Table I Caspase 8 enzyme activity of kidney tissue with ureteral obstruction (mean $\pm \mathrm{SE}$ )

\begin{tabular}{llllll}
\hline & $\begin{array}{l}\text { Group C } \\
(\mathbf{n}=\mathbf{6})\end{array}$ & $\begin{array}{l}\text { Group HES } \\
(\mathbf{n}=\mathbf{6})\end{array}$ & $\begin{array}{l}\text { Group UUO } \\
(\mathbf{n}=\mathbf{6})\end{array}$ & $\begin{array}{l}\text { Group UUO- } \\
\text { HES }(\mathbf{n}=\mathbf{6})\end{array}$ & $\begin{array}{l}\mathbf{p} \text {-value*** } \\
\text { Peritubular capillary }\end{array}$ \\
\hline $0.17 \pm 0.17$ & $0.83 \pm 0.17^{*}$ & $1.00 \pm 0.00^{*}$ & $1.00 \pm 0.00^{*}$ & $<0.0001$ \\
Glomerulus & $0.17 \pm 0.17$ & $0.33 \pm 0.21$ & $0.67 \pm 0.21$ & $0.83 \pm 0.17$ & 0.083 \\
Tubules & $0.00 \pm 0.00$ & $0.00 \pm 0.00$ & $0.00 \pm 0.00$ & $0.00 \pm 0.00$ & 1.000 \\
\hline
\end{tabular}

Notes: **Significance level with Kruskal-Wallis test, $p<0.05$. ${ }^{*} p<0.05$, compared with Group C.

Abbreviations: Group C, control; Group HES, hydroxyethyl starch solution 130/0.4; Group UUO, unilateral ureteral obstruction; Group UUO-HES, UUO-HES I30/0.4; SE, standard error. 
Table 2 Caspase 8 enzyme activity of kidney tissue without ureteral obstruction (mean \pm SE)

\begin{tabular}{lllllc}
\hline & $\begin{array}{l}\text { Group C } \\
(\mathbf{n}=\mathbf{6})\end{array}$ & $\begin{array}{l}\text { Group HES } \\
(\mathbf{n}=\mathbf{6})\end{array}$ & $\begin{array}{l}\text { Group UUO } \\
(\mathbf{n}=\mathbf{6})\end{array}$ & $\begin{array}{l}\text { Group UUO- } \\
\text { HES (n=6) }\end{array}$ \\
\hline Peritubular capillary & $0.00 \pm 0.00$ & $0.50 \pm 0.22$ & $0.83 \pm 0.17^{*}$ & $0.83 \pm 0.17^{*}$ & 0.005 \\
Glomerulus & $0.17 \pm 0.17$ & $0.33 \pm 0.21$ & $0.67 \pm 0.21$ & $0.83 \pm 0.17$ & 0.083 \\
Tubules & $0.00 \pm 0.00$ & $0.00 \pm 0.00$ & $0.00 \pm 0.00$ & $0.00 \pm 0.00$ & 1.000 \\
\hline
\end{tabular}

Notes: **Significance level with Kruskal-Wallis test, $p<0.05$. $* p<0.05$, compared with Group C.

Abbreviations: Group C, control; Group HES, hydroxyethyl starch solution I30/0.4; Group UUO, unilateral ureteral obstruction; Group UUO-HES, UUO-HES I30/0.4; SE, standard error.

( $p=0.001, p=0.001$, and $p<0.0001$, respectively). The cortical tubule and medullary tubule luminal caspase 3 activities were significantly higher in the UUO and UUO-HES groups than in the control and HES groups. The activity of caspase 3 in the corticomedullary tubular lumen was notably higher in the UUO and UUO-HES groups, compared to the control and UUO-HES groups (Table 5; Figures 1-4).

An important difference was observed among the groups without ureteral obstruction, regarding renal tissue tubule luminal caspase 3 activity ( $p=0.003$ ). The activity of the cortical tubule luminal caspase 3 was notably higher in the UUO and UUO-HES groups, as compared to the control and UUO-HES groups. The corticomedullary tubule and medullary tubule luminal caspase 3 activities were similar among the groups ( $p=0.152$ and $p=0.235$, respectively) (Table 6; Figures $1-4$ ).

A significant difference was noted among the groups with ureteral obstruction, in terms of degeneration of the renal tubular epithelium, as observed under a light microscope $(p<0.0001)$. Degeneration of the tubular epithelium was more frequently observed in the UUO and UUO-HES groups than in the control and HES groups (Table 7; Figures 5-8).

Notable differences were observed in the extent of edema in the tubular epithelium among the groups. In the UUO and UUO-HES groups, edema was more frequently observed in the tubular epithelium than in the control and HES groups. Furthermore, in the UUO-HES group, edema was more common in the tubular epithelium, as compared to the UUO group (Table 7; Figures 5-8).

Significant differences were observed in the extent of renal tubular dilation in groups with ureteral obstruction $(p<0.0001)$. Tubular dilation was more frequently observed in the UUO and UUO-HES groups than in the control and HES groups (Table 7; Figures 5-8).

Interstitial edema also showed significant differences among the groups $(p<0.0001)$. The UUO-HES group showed a greater extent of interstitial edema, in comparison with all other groups. Furthermore, interstitial edema was more frequently observed in the UUO group than the HES group (Table 7; Figures 5-8).

Significant differences were also noted in the levels of interstitial fibrosis observed among the groups $(p<0.0001)$. Interstitial fibrosis was more frequently observed in the UUO and UUO-HES groups than in the control and HES groups. Moreover, interstitial fibrosis was more prevalent in the UUO-HES group than in the UUO group (Table 7; Figures 5-8).

The levels of renal interstitial inflammation and renal tubular atrophy after ureteral obstruction were found to be significantly different among the groups $(p<0.0001)$. Interstitial inflammation and tubular atrophy were more prevalent in the UUO and UUO-HES groups than in the control and HES groups (Table 7; Figures 5-8).

The level of degeneration in the renal tubular epithelium, as observed under a light microscope, among groups without ureteral obstruction was found to be significantly different $(p=0.010)$. In the UUO-HES group, degeneration of the tubular epithelium was more prevalent than in all other groups $(p=0.005)$ (Table 8$)$.

The level of interstitial edema also showed significant differences among the groups. Interstitial edema was more

Table 3 Caspase 3 enzyme activity of kidney tissue with ureteral obstruction (mean \pm SE)

\begin{tabular}{lllllc}
\hline & $\begin{array}{l}\text { Group C } \\
(\mathbf{n}=\mathbf{6})\end{array}$ & $\begin{array}{l}\text { Group HES } \\
(\mathbf{n}=\mathbf{6})\end{array}$ & $\begin{array}{l}\text { Group UUO } \\
(\mathbf{n}=\mathbf{6})\end{array}$ & $\begin{array}{l}\text { Group UUO- } \\
\text { HES (n=6) }\end{array}$ \\
\hline Cortex tubule & $0.00 \pm 0.00$ & $0.17 \pm 0.17$ & $0.83 \pm 0.17^{*, 8}$ & $0.83 \pm 0.17^{*, 8}$ & $<$-value** \\
Corticomedullary tubule & $1.00 \pm 0.00$ & $1.00 \pm 0.00$ & $1.33 \pm 0.21$ & $1.67 \pm 0.21^{*, 8}$ & 0.013 \\
Medullary tubule & $0.17 \pm 0.17$ & $0.67 \pm 0.21$ & $1.50 \pm 0.22^{*, 8}$ & $1.83 \pm 0.17^{*, 8}$ & $<0.0001$ \\
Glomerulus & $0.00 \pm 0.00$ & $0.17 \pm 0.17$ & $1.50 \pm 0.22^{*, 8}$ & $1.67 \pm 0.21^{*, 8}$ & $<0.0001$ \\
\hline
\end{tabular}

Notes: **Significance level with Kruskal-Wallis test, $p<0.05$. ${ }^{*} p<0.05$, compared with Group $C$; ${ }^{*} p<0.05$, compared with Group HES.

Abbreviations: Group C, control; Group HES, hydroxyethyl starch solution 130/0.4; Group UUO, unilateral ureteral obstruction; Group UUO-HES, UUO-HES I30/0.4; SE, standard error. 


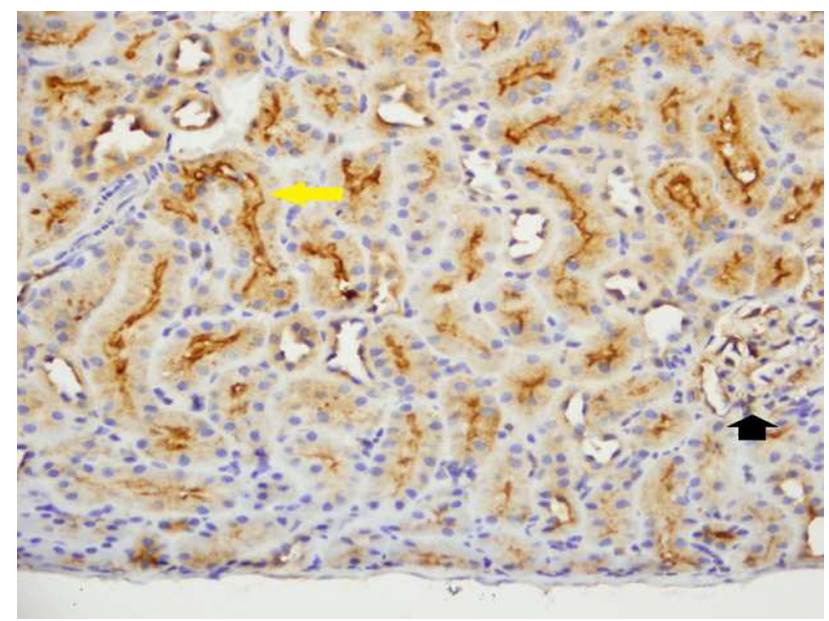

Figure I With caspase 3, mild luminal staining (yellow arrow) is noted in the cortex and corticomedullary tubules, whereas staining is not observed in glomeruli (black arrow) $(\times 400)$

prevalent in the UUO-HES group than in all other groups ( $p=0.003, p=0.003, p=0.014$, respectively) (Table 8 ).

Significant differences were also observed in serum MDA levels among the groups. The MDA levels were notably higher in the UUO and UUO-HES groups than in the control group $(p<0.0001$ and $p<0.0001$, respectively). In addition, MDA levels were notably higher in the UUO and UUO-HES groups than in the HES group $(p<0.0001$ and $p<0.0001$, respectively). The MDA levels in the UUO and UUO-HES groups were similar $(p=0.182)$ (Table 9).

Serum NO activity was compared among the groups and significant differences were observed. NO activity was notably higher in the UUO and UUO-HES groups, as compared to the control group ( $p=0.034$ and $p=0.001$,

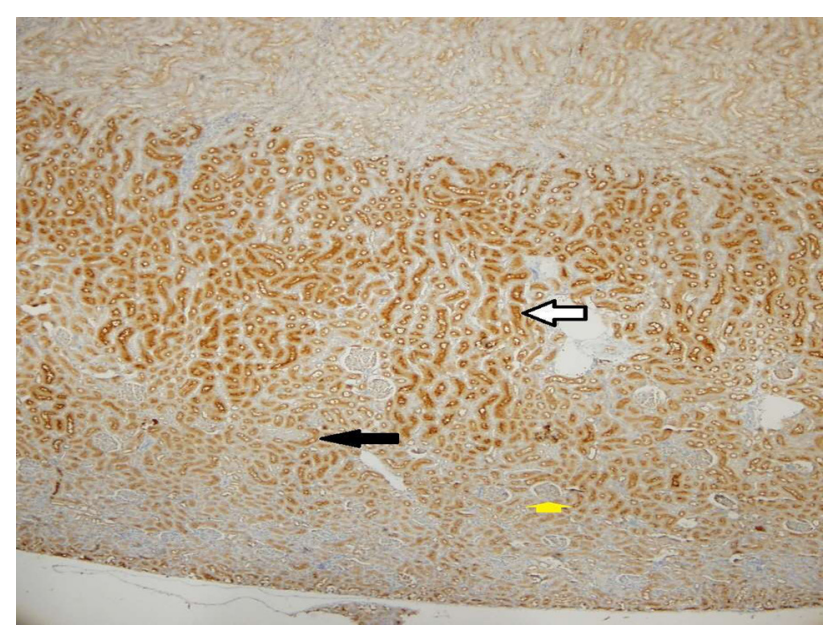

Figure 2 Caspase 3 showed intense luminal and cytoplasmic staining in the corticomedullary tubules (white arrow), whereas mild cytoplasmic staining was observed in the cortical tubules (black arrow). No staining was observed in the glomeruli (short yellow arrow) $(\times 40)$.

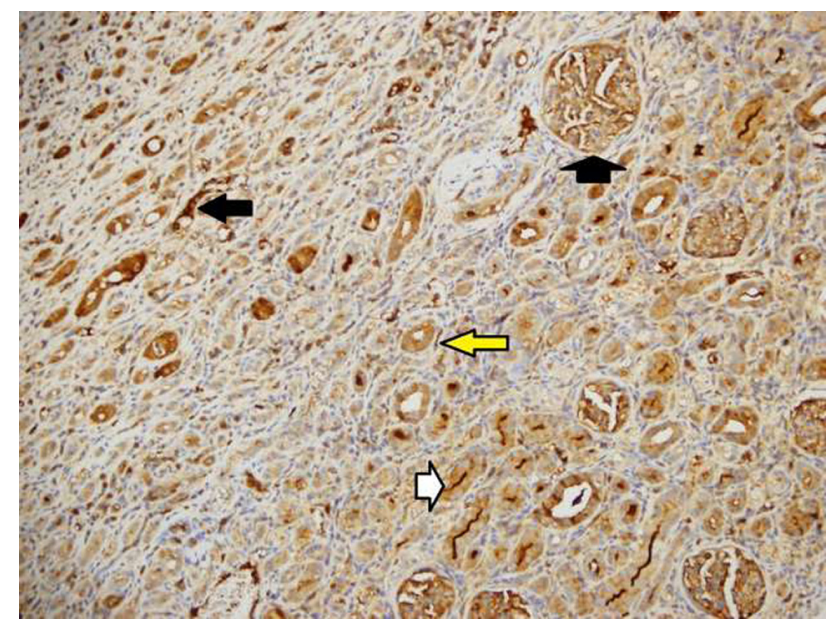

Figure 3 Caspase 3 showed luminal (white arrow) and mild cytoplasmic (yellow arrow) staining in the cortex and corticomedullary tubules; intense luminal/ cytoplasmic (long black arrow) staining in medullary tubules and intense cytoplasmic staining in glomeruli (short black arrow) $(\times 200)$.

respectively). Furthermore, $\mathrm{NO}$ activity was notably higher in the UUO-HES group than in the HES group ( $p=0.002$ ). NO activity in the UUO and UUO-HES groups was similar $(p=0.202)$ (Table 9).

Significant differences were noted in the levels of serum urea among the groups. Serum urea was notably higher in the UUO and UUO-HES groups, as compared to the control group ( $p<0.0001$ and $p<0.0001$, respectively). Moreover, serum urea was significantly higher in the UUO-HES group than in the HES group $(p=0.002)$. However, its levels were similar in the UUO and UUO-HES groups $(p=0.100)$ (Table 10).

Serum creatinine levels were significantly higher in the UUO and UUO-HES groups, as compared to the control

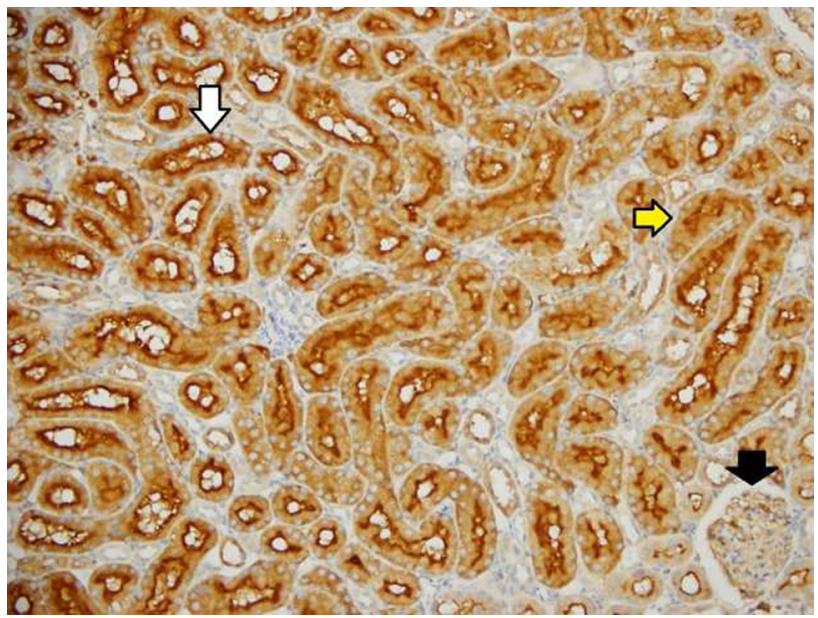

Figure 4 Caspase 3 showed light cytoplasmic staining (yellow arrow), intense luminal staining (white arrow) in cortical tubules, and light cytoplasmic staining in glomeruli (black arrow) $(\times 200)$. 
Table 4 Cytoplasmic caspase 3 enzyme activity of kidney tissue without ureteral obstruction (mean \pm SE)

\begin{tabular}{lllllc}
\hline & $\begin{array}{l}\text { Group C } \\
(\mathbf{n}=\mathbf{6})\end{array}$ & $\begin{array}{l}\text { Group HES } \\
(\mathbf{n}=\mathbf{6})\end{array}$ & $\begin{array}{l}\text { Group UUO } \\
(\mathbf{n}=\mathbf{6})\end{array}$ & $\begin{array}{l}\text { Group UUO- } \\
\text { HES (n=6) }\end{array}$ \\
\hline Cortex tubule & $0.00 \pm 0.00$ & $0.00 \pm 0.00$ & $0.17 \pm 0.17$ & $0.33 \pm 0.21$ & 0.269 \\
Corticomedullary tubule & $1.00 \pm 0.00$ & $1.00 \pm 0.00$ & $1.33 \pm 0.21$ & $1.50 \pm 0.22$ & 0.077 \\
Medullary tubule & $0.00 \pm 0.00$ & $0.67 \pm 0.21^{*}$ & $1.00 \pm 0.00^{*}$ & $1.17 \pm 0.17 *, 8$ & $<0.0001$ \\
Glomerulus & $0.00 \pm 0.00$ & $0.33 \pm 0.21$ & $0.50 \pm 0.22$ & $0.50 \pm 0.22$ & 0.235 \\
\hline
\end{tabular}

Notes: **Significance level with Kruskal-Wallis test, $p<0.05$. ${ }^{*} p<0.05$, compared with Group C; ${ }^{*} p<0.05$, compared with Group HES.

Abbreviations: Group C, control; Group HES, hydroxyethyl starch solution 130/0.4; Group UUO, unilateral ureteral obstruction; Group UUO-HES, UUO-HES I30/0.4; SE, standard error.

Table 5 Luminal caspase 3 enzyme activity of kidney tissue with ureteral obstruction (mean \pm SE)

\begin{tabular}{|c|c|c|c|c|c|}
\hline & $\begin{array}{l}\text { Group C } \\
(n=6)\end{array}$ & $\begin{array}{l}\text { Group HES } \\
(n=6)\end{array}$ & $\begin{array}{l}\text { Group UUO } \\
(n=6)\end{array}$ & $\begin{array}{l}\text { Group UUO- } \\
\text { HES }(n=6)\end{array}$ & $p$-value** \\
\hline Cortex tubule & $0.50 \pm 0.22$ & $0.67 \pm 0.21$ & $1.33 \pm 0.21^{*, 8}$ & $1.83 \pm 0.17^{*, 8}$ & 0.001 \\
\hline Corticomedullary tubule & $1.00 \pm 0.00$ & $1.33 \pm 0.21$ & $1.67 \pm 0.21 *$ & $2.00 \pm 0.00 *, 8$ & 0.001 \\
\hline Medullary tubule & $0.00 \pm 0.00$ & $0.00 \pm 0.00$ & $1.67 \pm 0.2 I^{*, 8}$ & $1.83 \pm 0.17^{*, 8}$ & $<0.000$ I \\
\hline
\end{tabular}

Notes: **Significance level with Kruskal-Wallis test, $p<0.05$. *p<0.05, compared with Group C; ${ }^{*} p<0.05$, compared with Group HES.

Abbreviations: Group C, control; Group HES, hydroxyethyl starch solution 130/0.4; Group UUO, unilateral ureteral obstruction; Group UUO-HES, UUO-HES I30/0.4; SE, standard error.

Table 6 Luminal caspase 3 enzyme activity of kidney tissue without ureteral obstruction (mean \pm SE)

\begin{tabular}{llllll}
\hline & $\begin{array}{l}\text { Group C } \\
(\mathbf{n}=\mathbf{6})\end{array}$ & $\begin{array}{l}\text { Group HES } \\
(\mathbf{n}=\mathbf{6})\end{array}$ & $\begin{array}{l}\text { Group UUO } \\
(\mathbf{n}=\mathbf{6})\end{array}$ & $\begin{array}{l}\text { Group UUO- } \\
\text { HES (n=6) }\end{array}$ \\
\hline Cortex tubule & $0.17 \pm 0.17$ & $0.67 \pm 0.21$ & $0.83 \pm 0.17^{*}$ & $1.33 \pm 0.21^{*, 8}$ & 0.003 \\
Corticomedullary tubule & $1.00 \pm 0.00$ & $1.17 \pm 0.31$ & $1.50 \pm 0.22$ & $1.67 \pm 0.21$ & 0.152 \\
Medullary tubule & $0.00 \pm 0.00$ & $0.00 \pm 0.00$ & $0.17 \pm 0.17$ & $0.50 \pm 0.34$ & 0.235 \\
\hline
\end{tabular}

Notes: **Significance level with Kruskal-Wallis test, $p<0.05$. ${ }^{*} p<0.05$, compared with Group $C$; ${ }^{\star} p<0.05$, compared with Group HES.

Abbreviations: Group C, control; Group HES, hydroxyethyl starch solution 130/0.4; Group UUO, unilateral ureteral obstruction; Group UUO-HES, UUO-HES I30/0.4; SE, standard error.

Table 7 Histological evaluation of kidney tissue with ureteral obstruction (mean \pm SE)

\begin{tabular}{|c|c|c|c|c|c|}
\hline & $\begin{array}{l}\text { Group C } \\
(n=6)\end{array}$ & $\begin{array}{l}\text { Group HES } \\
(n=6)\end{array}$ & $\begin{array}{l}\text { Group UUO } \\
(n=6)\end{array}$ & $\begin{array}{l}\text { Group UUO- } \\
\text { HES }(n=6)\end{array}$ & $p$-value** \\
\hline Degeneration in tubule epithelium & $0.00 \pm 0.00$ & $0.50 \pm 0.22$ & $2.40 \pm 0.60^{*, \&}$ & $3.00 \pm 0.00 *, \&$ & $<0.0001$ \\
\hline Edema in the tubule epithelium & $0.00 \pm 0.00$ & $0.00 \pm 0.00$ & $1.80 \pm 0.58^{*, 8}$ & $3.00 \pm 0.00 *, \&,+$ & $<0.000$ I \\
\hline Tube dilatation & $0.00 \pm 0.00$ & $0.33 \pm 0.21$ & $2.60 \pm 0.40^{*, 8}$ & $3.00 \pm 0.00 *, \&$ & $<0.0001$ \\
\hline Interstitial edema & $0.00 \pm 0.00$ & $0.50 \pm 0.34$ & $1.00 \pm 0.00 *$ & $2.83 \pm 0.17^{*, \&,+}$ & $<0.0001$ \\
\hline Interstitial fibrosis & $0.00 \pm 0.00$ & $0.00 \pm 0.00$ & $1.40 \pm 0.5 I^{*, 8}$ & $2.83 \pm 0.17^{*, \&,+}$ & $<0.0001$ \\
\hline Interstitial inflammation & $0.00 \pm 0.00$ & $0.00 \pm 0.00$ & $2.40 \pm 0.60^{*, \&}$ & $2.67 \pm 0.21^{*, 2}$ & $<0.000$ I \\
\hline Glomerular sclerosis (global/segmental) & $0.00 \pm 0.00$ & $0.00 \pm 0.00$ & $0.00 \pm 0.00$ & $0.00 \pm 0.00$ & 1.000 \\
\hline Bowman capsule dilatation & $0.00 \pm 0.00$ & $0.00 \pm 0.00$ & $0.00 \pm 0.00$ & $0.00 \pm 0.00$ & 1.000 \\
\hline Tubular atrophy & $0.00 \pm 0.00$ & $0.00 \pm 0.00$ & $2.20 \pm 0.58^{*, 8}$ & $2.67 \pm 0.21^{*, 8}$ & $<0.0001$ \\
\hline
\end{tabular}

Notes: **Significance level with Kruskal-Wallis test, $p<0.05$. ${ }^{*} p<0.05$, compared with Group C; ${ }^{8} p<0.05$, compared with Group HES; ${ }^{+} p<0.05$, compared with Group UUO.

Abbreviations: Group C, control; Group HES, hydroxyethyl starch solution I30/0.4; Group UUO, unilateral ureteral obstruction; Group UUO-HES, UUO-HES I30/0.4; $\mathrm{SE}$, standard error.

group ( $p=0.043$ and $p=0.001$, respectively). In addition, serum creatinine was significantly higher in the UUO-HES group than in the HES group ( $p=0.001)$, and similar levels were observed in the UUO and UUO-HES groups $(p=0.57)$ (Table 10).

\section{Discussion}

Surgical UUO, as a model of progressive chronic kidney disease, has been used in a variety of experimental animals. The fact that apoptosis progresses in obstructed renal tubules have been well established. ${ }^{22}$ Apoptosis, as a form 


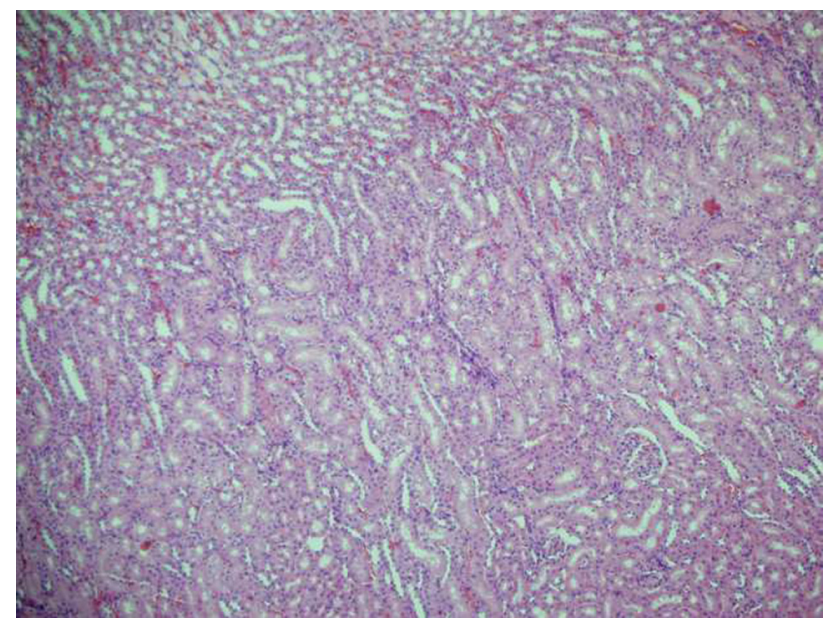

Figure 5 Normal histomorphologic cortex and medulla (hematoxylin and eosin stain, $\times 100)$.

of programmed cell death, occurs during development and post-development pathogenesis. Particularly when tissues or organs go through pathological processes such as ischemia, hypoxia, toxicity, and metabolic stress, cells may undergo apoptosis. ${ }^{23-25}$ Apoptotic renal tubular cell death is activated by tumor necrosis factor alpha (TNF- $\alpha$ ), via activation of death receptor signaling and caspase $8 .^{26}$ In the present study, peritubular capillary caspase 8 activity in ureter-obstructed rats was notably higher in all groups than in the control group. However, glomerular and tubular caspase 8 activity was similar among all groups. For rats without ureteral obstruction, peritubular capillary caspase 8 activity was significantly higher in the UUO and UUO-HES groups, as compared to the control group. Glomerular and tubular caspase 8 activity was similar among the groups.

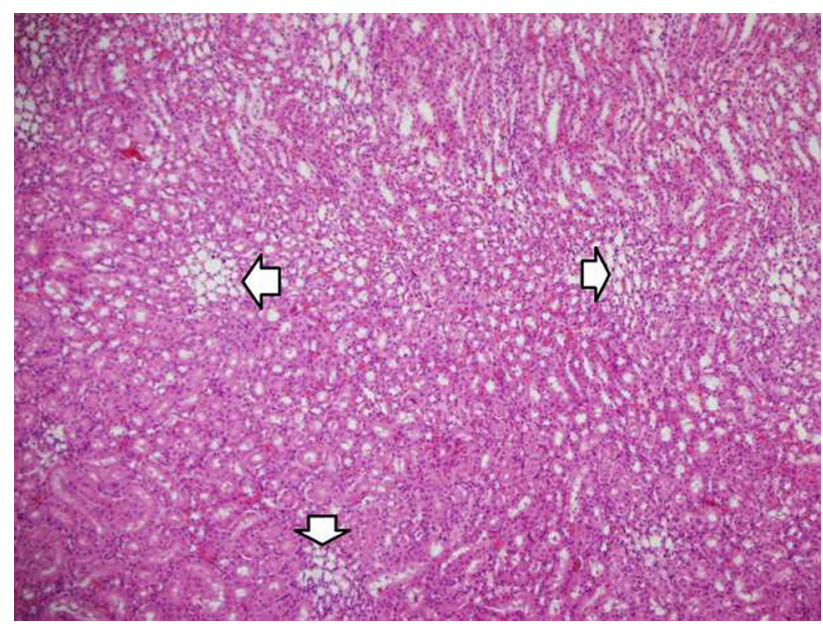

Figure 6 Hydroxyethyl starch (HES) group showing interstitial edema (white arrows) (hematoxylin and eosin stain, $\times 100$ ).

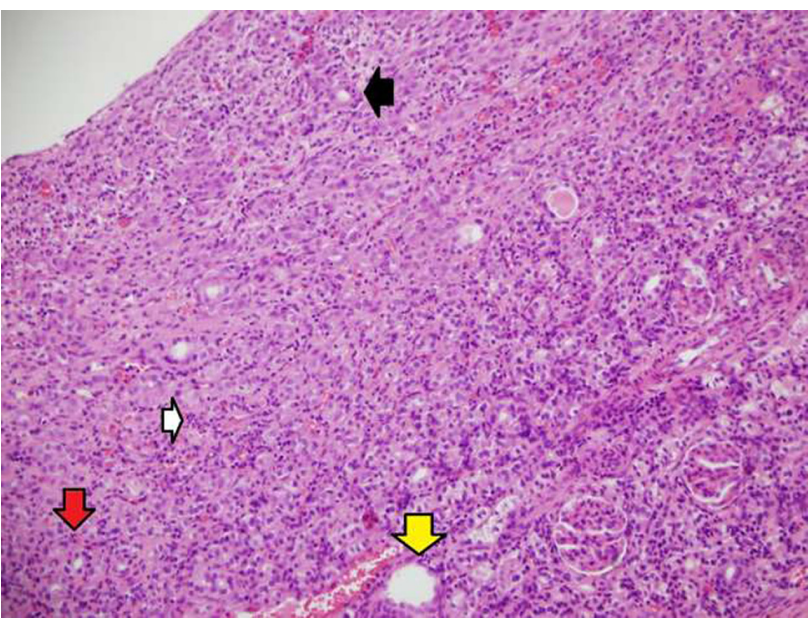

Figure 7 Degeneration and edema in the tubular epithelium, tubular dilatation (yellow arrow), tubular atrophy (black arrow), interstitial inflammation (white arrow), and interstitial fibrosis (red arrow) are severe. Mild interstitial edema is noticeable (hematoxylin and eosin stain, $\times 400$ ).

A significant increase in the number of apoptotic and proliferative tubular cells in inducible-NO synthase gene knockout mice, following unilateral obstructive nephropathy, was reportedly an indicative of the anti-apoptotic properties of NO, as demonstrated by Miyajima et al. ${ }^{27}$ Even though NO has complex effects on renal oxidative status, it exerts important anti-apoptotic protective effects in UUO. ${ }^{28}$ Felsen et $\mathrm{al}^{29}$ subjected cultured tubular epithelial cells to mechanical stretch as, an in vitro replication of UUO-induced tubular cellular stress to study the role of $\mathrm{NO}$ in apoptosis during UUO.

The NO activity was significantly higher in the UUO and UUO-HES groups than in the control group. Furthermore,

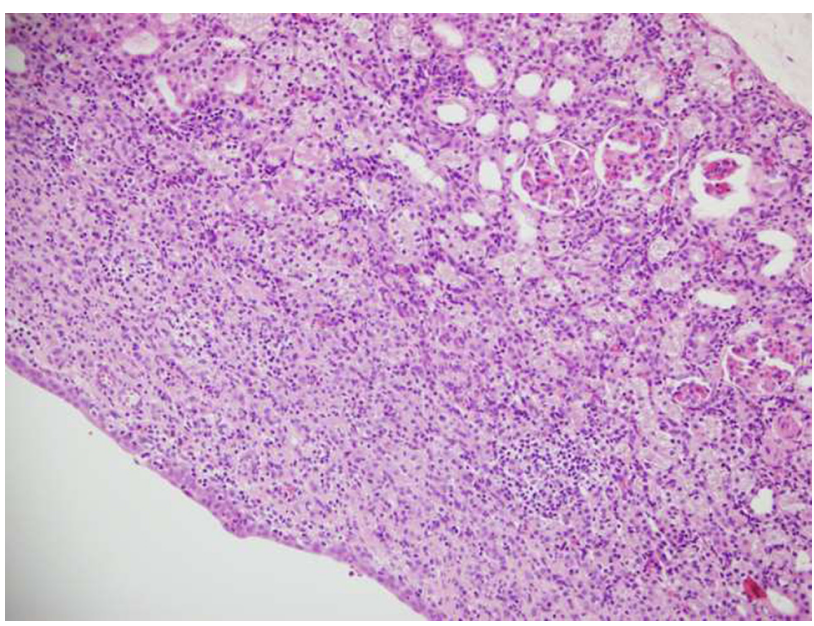

Figure 8 Hydroxyethyl starch (HES) in the obstructive kidney. Degeneration in the tubular epithelium, edema in the tubular epithelium, tubular dilatation, tubular atrophy, interstitial inflammation, and interstitial fibrosis are severe. Mild interstitial edema is noticeable (hematoxylin and eosin stain, $\times 200$ ). 
Table 8 Histological evaluation of kidney tissue without ureteral obstruction (mean \pm SE)

\begin{tabular}{lllllc}
\hline & $\begin{array}{l}\text { Group C } \\
(\mathbf{n}=\mathbf{6})\end{array}$ & $\begin{array}{l}\text { Group HES } \\
(\mathbf{n}=\mathbf{6})\end{array}$ & $\begin{array}{l}\text { Group UUO } \\
(\mathbf{n}=\mathbf{6})\end{array}$ & $\begin{array}{l}\text { Group UUO- } \\
\text { HES }(\mathbf{n}=\mathbf{6})\end{array}$ \\
\hline Degeneration in tubule epithelium & $0.00 \pm 0.00$ & $0.00 \pm 0.00$ & $0.00 \pm 0.00$ & $0.50 \pm 0.21^{*, \&,+}$ & 0.010 \\
Edema in the tubule epithelium & $0.00 \pm 0.00$ & $0.00 \pm 0.00$ & $0.00 \pm 0.00$ & $0.00 \pm 0.00$ & 1.000 \\
Tubular dilatation & $0.00 \pm 0.00$ & $0.00 \pm 0.00$ & $0.00 \pm 0.00$ & $0.17 \pm 0.17$ & 0.413 \\
Interstitial edema & $0.00 \pm 0.00$ & $0.00 \pm 0.00$ & $0.17 \pm 0.17$ & $0.83 \pm 0.31^{*, \&,+}$ & 0.008 \\
Interstitial fibrosis & $0.00 \pm 0.00$ & $0.00 \pm 0.00$ & $0.00 \pm 0.00$ & $0.00 \pm 0.00$ & 1.000 \\
Interstitial inflammation & $0.00 \pm 0.00$ & $0.00 \pm 0.00$ & $0.00 \pm 0.00$ & $0.50 \pm 0.21^{*, \varepsilon,+}$ & 0.010 \\
Glomerular sclerosis (global/segmental) & $0.00 \pm 0.00$ & $0.00 \pm 0.00$ & $0.00 \pm 0.00$ & $0.00 \pm 0.00$ & 1.000 \\
Bowman capsule dilatation & $0.00 \pm 0.00$ & $0.00 \pm 0.00$ & $0.00 \pm 0.00$ & $0.00 \pm 0.00$ & 1.000 \\
Tubular atrophy & $0.00 \pm 0.00$ & $0.00 \pm 0.00$ & $0.00 \pm 0.00$ & $0.00 \pm 0.00$ & 1.000 \\
\hline
\end{tabular}

Notes: **Significance level with Kruskal-Wallis test, $p<0.05$. ${ }^{*} p<0.05$, compared with Group C; ${ }^{*} p<0.05$, compared with Group HES; ${ }^{+} p<0.05$, compared with Group UUO.

Abbreviations: Group C, control; Group HES, hydroxyethyl starch solution 130/0.4; Group UUO, unilateral ureteral obstruction; Group UUO-HES, UUO-HES I30/0.4; SE, standard error.

NO activity in the UUO-HES group was significantly higher than in the HES group. The NO activity was similar in the UUO and UUO-HES groups ( $p=0.202)$. Obstructed kidney tissues had significantly higher $\mathrm{NO}$ activities.

In rats with ureteral obstruction, caspase 3 activity in the cortical tubule, medullary tubule, and glomerular endoplasmic reticulum was found to be significantly higher in the UUO and UUO-HES groups, as compared to the control and HES groups. In addition, corticomedullary tubulo-cytoplasmic caspase 3 activity was significantly higher in the UUO-HES group, as compared to the control and HES groups. Furthermore, in rats with ureteral obstruction, the activity of caspase 3 was significantly higher in all groups, as compared to the control. The medullary tubule cytoplasmic activity of caspase-3 was notably higher in the UUO-HES group than in the HES group. However, caspase- 3 activity was similar in the cortical tubules, corticomedullary tubules, and glomerular cytoplasm, among all groups. In rats with ureteral obstruction, the cortical tubule and medullary tubule luminal activity of caspase-3 was significantly higher in the UUO and UUO-HES groups, as compared to the control and HES groups. The caspase-3 activity in the corticomedullary tubular lumen was significantly higher in the UUO and UUO-HES groups, as compared to the control group. In rats without ureteral obstruction, the activity of cortical tubule luminal caspase- 3 was significantly higher in the UUO and UUO-HES groups, as compared to the control group. The corticomedullary tubule and medullary tubule luminal caspase- 3 activities were similar among the groups.

Oxidative stress plays an important role in tubulointerstitial damage in renal injury induced by UUO. ${ }^{30}$ Reduced expression of superoxide dismutase and increased expression of nicotinamide adenine dinucleotide phosphate (NADPH) oxidase are related to fibrosis, which is characteristic of chronic kidney disease. ${ }^{31}$ In the present study, interstitial edema was more common in the UUO-HES group than in any other groups. Furthermore, interstitial edema was more common in the UUO group, as compared to the HES group, and interstitial fibrosis was more common in the UUO and UUO-HES groups than in the control and HES groups. Moreover, interstitial fibrosis was more prevalent in the UUO-HES group than in the UUO group. Fibrosis is a common outcome of all forms of renal injury. Fibrosis, as evidenced by the accumulation of the extracellular matrix and cellular phenotypic alterations, is considered a key player in the loss of renal function. ${ }^{32}$

Interstitial inflammation was more prevalent in the UUO and UUO-HES groups than in the control and HES groups. Tubular atrophy was also more prevalent in the UUO and

Table 9 Oxidative status parameters (mean \pm SE)

\begin{tabular}{|c|c|c|c|c|c|}
\hline & $\begin{array}{l}\text { Group C } \\
(n=6)\end{array}$ & $\begin{array}{l}\text { Group HES } \\
(n=6)\end{array}$ & $\begin{array}{l}\text { Group UUO } \\
(n=6)\end{array}$ & $\begin{array}{l}\text { Group UUO- } \\
\text { HES }(n=6)\end{array}$ & $p$-value** \\
\hline Malondialdehyde (MDA) (nmol/mL) & $5.45 \pm 1.20$ & $8.88 \pm I .14$ & $\mid 6.45 \pm 1.31 *, 8$ & $20.50 \pm 1.28^{*, 2}$ & $<0.000 \mathrm{I}$ \\
\hline Nitric oxide (NO) (umol/L) & $16.74 \pm 3.30$ & $23.10 \pm 6.20$ & $41.10 \pm 6.40 *$ & $60.50 \pm \mid 1.24^{*}, 8$ & 0.003 \\
\hline
\end{tabular}

Notes: **Significance level with Kruskal-Wallis test, $p<0.05$. ${ }^{*} p<0.05$, compared with Group $C$; ${ }^{\star} p<0.05$, compared with Group HES.

Abbreviations: Group C, control; Group HES, hydroxyethyl starch solution 130/0.4; Group UUO, unilateral ureteral obstruction; Group UUO-HES, UUO-HES I30/0.4; SE, standard error. 
Table 10 Urea and creatinine findings in ureteral obstructed rats (mean $\pm \mathrm{SE}$ )

\begin{tabular}{llllll}
\hline & $\begin{array}{l}\text { Group C } \\
(\mathbf{n}=\mathbf{6})\end{array}$ & $\begin{array}{l}\text { Group HES } \\
(\mathbf{n}=\mathbf{6})\end{array}$ & $\begin{array}{l}\text { Group UUO } \\
(\mathbf{n}=\mathbf{6})\end{array}$ & $\begin{array}{l}\text { Group UUO- } \\
\text { HES }(\mathbf{n}=\mathbf{6})\end{array}$ \\
\hline Urea $(\mathrm{mg} / \mathrm{dL})$ & $33.33 \pm 3.50$ & $38.92 \pm 2.20$ & $52.33 \pm 2.59^{*}$ & $58.93 \pm 3.11^{*, 8}$ & $<0.0001$ \\
Creatinine $(\mathrm{mg} / \mathrm{dL})$ & $0.39 \pm 0.03$ & $0.41 \pm 0.03$ & $0.66 \pm 0.12^{*}$ & $0.87 \pm 0.13^{*, 8}$ & 0.002 \\
\hline
\end{tabular}

Notes: **Significance level with Kruskal-Wallis test, $p<0.05$. ${ }^{*} p<0.05$, compared with Group $C ;{ }^{*} p<0.05$, compared with Group HES.

Abbreviations: Group C, control; Group HES, hydroxyethyl starch solution I30/0.4; Group UUO, unilateral ureteral obstruction; Group UUO-HES, UUO-HES I30/0.4; SE, standard error.

UUO-HES groups than in the control and HES groups. Renal glomerular sclerosis (global/segmental) and Bowman's capsule dilatation were found to be similar among the groups with ureteral obstruction. Severe and extensive damage was observed on histopathological examination of the kidney tissues following UUO. This is possibly because of highly reactive free radicals produced due to the oxidative stress, following UUO.

One of the most important mechanisms associated with free-radical-induced cell injury is lipid peroxidation. ${ }^{33}$ Although the production of MDA, as a result of the oxidation of polyunsaturated fatty acids on the cell membrane, is not specific, it is one of the most important indicators of lipid peroxidation, and it is strongly correlated with the extent of peroxidation. ${ }^{34}$

Chronic inflammation is common among patients with chronic kidney disease, especially those on dialysis therapy (hemodialysis, peritoneum dialysis). ${ }^{35}$ The ROS that is produced excessively by active neutrophils causes tissue injury in inflammatory diseases. ${ }^{36}$ Although MDA degrades aminophospholipid organization of the erythrocyte membrane, it is reported effective against the cellular injury. ${ }^{37}$

In a previous study, 40 out of 80 rats were selected to perform UUO, where the renal tissues were removed and examined at the end of 2 nd and 4 th week. Over those 4 weeks, oxidative stress showed a progressive increase and antioxidant levels were reduced, following the ureteral obstruction. The MDA levels were also significantly higher, suggestive of higher levels of lipid peroxidation, an indicator of oxidative stress. ${ }^{33}$ Previous studies have reported renal fibrosis and apoptosis caused by oxidative stress, due to ureteral obstruction. . $^{13,14,38}$

MDA, a stable lipid hydroperoxide, is an indicator of lipid peroxidation in biological tissues. ${ }^{39}$ The MDA levels were significantly higher in the UUO and UUO-HES groups than in the control group. Furthermore, MDA was significantly higher in the UUO and UUO-HES groups, as compared to the HES group. Moreover, MDA levels were similar in the UUO and UUO-HES groups. In the present study, MDA levels were generally increased in the UUO groups.
Dursun et $\mathrm{a}^{40}$ observed a significant increase in serum urea and creatinine levels in rats with experimentally induced ureteral obstruction, with amorphous eruptions, cellular swelling, vacuolization, the presence of neutrophils in the glomerulus, tubular dilatation, and increased vascular congestion in the tubular lumen histopathologically. ${ }^{40}$

We also found that renal function was severely impaired in the UUO groups. Levels of serum urea were significantly higher in the UUO and UUO-HES groups, as compared to the control group. In addition, serum urea was significantly higher in the UUO-HES group, as compared to the HES group $(p=0.002)$. However, serum urea levels were similar in the UUO and UUOHES groups. Serum creatinine levels were significantly higher in the UUO and UUO-HES groups, as compared to the control group. Furthermore, serum creatinine was significantly higher in the UUO-HES group than in the HES group.

Based on the foregoing results, we propose that HES can be used with caution, and if indicated, in cases of UUO. However, it should not be used in cases of bilateral ureteral obstruction. Other aspects of these findings, including the clinical significance and practical applications, merit further experimental and clinical investigation.

\section{Acknowledgment}

The abstract of our manuscript was accepted for oral presentation at the 23rd Annual Congress of the Cardiothoracic and Vascular Anesthesia and Intensive Care Society - 2017.

\section{Disclosure}

The authors report no conflicts of interest in this work.

\section{References}

1. Boldt J, Lenz M, Kumle B, Papsdorf M. Volume replacement strategies in intensive care units: results from a postal survey. Intensive Care Med. 1998;24(2):147-151.

2. Schortgen F, Girou E, Deye N, Brochard L; CRYCO Study Group, The risk associated with hyperoncotic colloids in patients with shock Intensive Care Med. 2008;34(12):2157-2168.

3. Schortgen F, Lacherade JC, Bruneel F, et al. Effects of hydroxyethylstarch and gelatin on renal function in severe sepsis: a multicentre randomised study. Lancet. 2001;357(9260):911-916. 
4. Brunkhorst F, Engel C, Bloos F, et al. German competence network sepsis (SepNet): intensive insulin therapy and pentastarch resuscitation in severe sepsis. N Engl J Med. 2008;358(2):125-139.

5. Jungheinrich C, Neff TA. Pharmacokinetics of hydroxyethyl starch. Clin Pharmacokinet. 2005;44(7):681-699.

6. Westphal M, James MF, Kozek-Langenecker S, Stocker R, Guidet B, Van Aken H. Hydroxyethyl starches: different products - different effects. Anesthesiology. 209;111(1):187-202.

7. Alavi SM, Ahmadi BB, Baharestani B, Babaei T. Comparison of the effects of gelatin, Ringer's solution and a modern hydroxyl ethyl starch solution after coronary artery bypass graft surgery. Cardiovasc J Afr. 2012;23(8):428-431.

8. Datzmann T, Hoenicka M, Reinelt H, Liebold A, Gorki H. Influence of $6 \%$ hydroxyethyl starch 130/0.4 versus crystalloid solution on structural renal damage markers after coronary artery bypass grafting: a post hoc subgroup analysis of a prospective trial. J Cardiothorac Vasc Anesth. 2018;32(1):205-211.

9. Skhirtladze K, Base EM, Lassnigg A, et al. Comparison of the effects of albumin 5\%, hydroxyethyl starch 130/0.4 6\%, and Ringer's lactate on blood loss and coagulation after cardiac surgery. Br J Anaesth. 2014;112(2):255-264.

10. Lagny MG, Roediger L, Koch JN, et al. Hydroxyethyl starch 130/0.4 and the risk of acute kidney injury after cardiopulmonary bypass: a single-center retrospective study. J Cardiothorac Vasc Anesth. 2016;30(4):869-875.

11. Cho JE, Shim JK, Song JW, Lee HW, Kim DH, Kwak YL. Effect of $6 \%$ hydroxyethyl starch $130 / 0.4$ as a priming solution on coagulation and inflammation following complex heart surgery. Yonsei Med J. 2014;55:625-634.

12. Schortgen F, Brochard L. Colloid-induced kidney injury: experimental evidence may help to understand mechanisms. Crit Care. 2009;13(2):130.

13. Correa-Costa M, Semedo P, Monteiro AP, et al. Induction of heme oxygenase-1 can halt and even reverse renal tubuleinterstitial fibrosis. PLoS One. 2010;5(12):e14298.

14. Morisada N, Nomura M, Nishii H, et al. Complete disruption of all nitric oxide synthase genes causes markedly accelerated renal lesion formation following unilateral ureteral obstruction in mice in vivo. J Pharmacol Sci. 2010;114(4):379-389.

15. Okamura DM, Pasichnyk K, Lopez-Guisa JM, et al. Galectin-3 preserves renal tubules and modulates extracellular matrix remodeling in progressive fibrosis. Am J Physiol Renal Physiol. 2011;300(1):F245-F253.

16. Ferraro E, Cecconi F. Autophagic and apoptotic response to stress signals in mammalian cells. Arch Biochem Biophys. 2007;462(2):210-219.

17. Cohen GM. Caspases: the executioners of apoptosis. Biochem J. 1997;326(Pt 1):1-16.

18. Siragy HM, Bedigian M. Mechanism of action of angiotensin-receptor blocking agents. Curr Hypertens Rep. 1999;1(4):289-295.

19. Esterbauer H, Cheeseman KH. Determination of aldehydic lipid peroxidation products: malonaldehyde and 4-hydroxynonenal. Methods Enzymol. 1990;186:407-421.

20. Cortas NK, Wakid NW. Determination of inorganic nitrate in serum and urine by a kinetic cadmium-reduction method. Clin Chem. 1990; 36(8 Pt 1):1440-1443.
21. Jaffé M. Ueber den Niederschlag, welchen Pikrinsäure in normalem Harn erzeugt und über eine neue Reaktion des Kreatinins. Z Physiol Chem. 1886;10(5):391-400. German.

22. Chevalier RL. Pathogenesis of renal injury in obstructive uropathy. Curr Opin Pediatr. 2006;18(2):153-160.

23. Wei Q, Dong G, Chen JK, Ramesh G, Dong Z. Bax and Bak have critical roles in ischemic acute kidney injury in global and proximal tubulespecific knockout mouse models. Kidney Int. 2013;84(1):138-148.

24. Bhatt K, Wei Q, Pabla N, et al. MicroRNA-687 induced by hypoxiainducible factor-1 targets phosphatase and tensin homolog in renal ischemiareperfusion injury. J Am Soc Nephrol. 2015;26(7):1588-1596.

25. Eizirik DL, Millard I. Chronicle of a death foretold: endoplasmic reticulum stress and beta cell apoptosis in diabetes. Med Sci (Paris). 2014;30(5):496-499.

26. Misseri R, Meldrum DR, Dinarello CA, et al. TNF-alpha mediates obstruction-induced renal tubular cell apoptosis and proapoptotic signaling. Am J Physiol Renal Physiol. 2005;288(2):F406-F411.

27. Miyajima A, Chen J, Poppas DP, Vaughan ED Jr, Felsen D. Role of nitric oxide in renal tubular apoptosis of unilateral ureteral obstruction. Kidney Int. 2001;59(4):1290-1303.

28. Modlinger PS, Wilcox CS, Aslam S. Nitric oxide, oxidative stress, and progression of chronic renal failure. Semin Nephrol. 2004;24(4):354-365.

29. Felsen D, Diaz BJ, Chen J, et al. Pressure and stretch differentially affect proliferation of renal proximal tubular cells. Physiol Rep. 2017; 5(17):e13346.

30. Kramer AB, van der Meulen EF, Hamming I, van Goor H, Navis G. Effect of combining ACE inhibition with aldosterone blockade on proteinuria and renal damage in experimental nephrosis. Kidney Int. 2007;71(5):417-424.

31. Vaziri ND, Dicus M, Ho ND, Boroujerdi-Rad L, Sindhu RK. Oxidative stress and dysregulation of superoxide dismutase and NADPH oxidase in renal insufficiency. Kidney Int. 2003;63(1):179-185.

32. Eddy AA. Molecular basis of renal fibrosis. Pediatr Nephrol. 2000; 15(3-4):290-301.

33. Özer Ç, Gönül B. The effect of ascorbic acid administration on the liver oxidant processes in diabetic rats. Gazi Med J. 2006;17:196-199.

34. Halliwell B, Chirico S. Lipid peroxidation: its mechanism, measurement, and significance. Am J Clin Nutr. 1993;57(5 Suppl):715S-724S.

35. Amore A, Coppo R. Immunological basis of inflammation in dialysis. Nephrol Dial Transplant. 2002;17(Suppl 8):16-24.

36. Weiss SL. Tissue destruction by neutrophils. NEng J Med. 1989;320(6): 365-376.

37. Uchida K. Role of reactive aldehyde in cardiovascular disease. Free Radical Biol Med. 2000;28(12):1685-1696.

38. Zhou TB, Qin YH, Lei FY, Huang WF, Drummen GP. Association of prohibitin-1 and 2 with oxidative stress in rats with renal interstitial fibrosis. Mol Biol Rep. 2014;41(15):3033-3043.

39. Kuhad A, Tirkey N, Pilkhwal S, Chopra K. Effect of Spirulina, a blue green algae, on gentamicin induced oxidative stress and renal dysfunction in rats. Fundam Clin Pharmacol. 2006;20(2):121-128.

40. Dursun KA, Akyol İ, Karademir K, et al. The role of free oxygen radicals in üreteral obstructions and the effects of verapamil and alfa tocopherol for treatment. Türk Üroloji Dergisi. 2000;26:437-443.
Drug Design, Development and Therapy

\section{Publish your work in this journal}

Drug Design, Development and Therapy is an international, peerreviewed open-access journal that spans the spectrum of drug design and development through to clinical applications. Clinical outcomes, patient safety, and programs for the development and effective, safe, and sustained use of medicines are the features of the journal, which

\section{Dovepress}

has also been accepted for indexing on PubMed Central. The manuscript management system is completely online and includes a very quick and fair peer-review system, which is all easy to use. Visit http://www.dovepress.com/testimonials.php to read real quotes from published authors. 